\title{
CULTIVO DE FEIJOEIRO EM DIFERENTES SISTEMAS DE PREPARO DO SOLO NO NOROESTE PAULISTA
}

\author{
SOUZA, Wilson José Oliveira ${ }^{77}$ \\ SANTOS, Isabela Zocal dos ${ }^{78}$
}

Recebido em: 2008-06-16

Aprovado em: $2008-07-20$

ISSUE DOI: $10.3738 / 1982.2278 .76$

RESUMO: O experimento foi conduzido na Fazenda de Ensino e Pesquisa da Universidade Camilo Castelo Branco - UNICASTELO, Campus de Fernandópolis, SP, com o objetivo de estudar os efeitos de diferentes sistemas de preparo do solo sobre o comportamento da cultura do feijoeiro no período de inverno. Adotou-se delineamento de blocos casualizados (DBC), com três tratamentos e quatro repetições, em parcelas de $1,5 \mathrm{~m}^{2}$ de área, com dimensões de $1,5 \times 1,0 \mathrm{~m}$. Os tratamentos utilizados foram: PC: semeadura convencional de feijão, com revolvimento do solo e controle mecânico de plantas daninhas; CM: sistema de cultivo mínimo de feijão no inverno, com revolvimento mínimo do solo e controle químico de plantas daninhas; PD: semeadura de feijão em sistema de plantio direto no inverno e controle químico de plantas daninhas. Avaliou-se o desenvolvimento das plantas de feijoeiro, a produção de matéria seca e produção de grãos. Os dados obtidos mostraram que o desenvolvimento médio das plantas de feijoeiro foi maior no sistema de plantio direto. Todos os sistemas de preparo estudados mostraram produção de matéria seca e de grãos semelhantes, indicando que o maior desenvolvimento não se refletiu nestes parâmetros. Há necessidade de se prolongar os estudos nestas condições, para que resultados mais conclusivos sejam obtidos.

Palavras-chave: Feijão. Plantio direto. Plantio convencional. Cultivo mínimo. Matéria seca.

\section{BEAN CULTIVATION UNDER DIFFERENT PRODUCTION SYSTEMS IN THE NORTHEASTERN OF SÃO PAULO STATE}

SUMMARY: The experiment was carried out at the Research Farm, Camilo Castelo Branco University, UNICASTELO, Fernandópolis (SP). It aimed at studying the effects of different soil preparation systems about the behaviour of bean culture in winter. The experimental area was carried out in randomized blocks with three treatments and four replications with plot dimension of $1.0 \times 1.5 \mathrm{~m}\left(1.5 \mathrm{~m}^{2}\right)$. The treatments used were PC: bean yields under conventional tillage in winter and mechanic control of weeds; CM: bean yields under minimum tillage in winter and chemical control of weeds; PD: bean yields under direct tillage in winter and chemical control of weeds. This study evaluated the dry matter production, the plant development and the bean production. The data showed that the average bean development was higher under the direct tillage system. All the production systems studied showed both dry matter and grain productions are similar, demonstrating that the highest development couldn't be observed under these conditions. It is necessary to keep on studying these kinds of conditions in order to obtain more consistent results.

Keywords: Beans. Direct tillage. Conventional tillage. Minimum tillage. Dry matter.

\footnotetext{
${ }^{77}$ Doutor em Agronomia (FCAV/UNESP).Docente pesquisador na área de solos e mecanização com ênfase em produção sustentável. Consultor na área de solos e planejamento. souzaw @uol.com.br

${ }^{78}$ Engenheira Agrônoma pela UNICASTELO, Campus de Fernandópolis (SP). Pós-graduanda em Cultura da cana-de-açúcar: produção e tecnologia (Lato sensu) na mesma instituição. belazocal@ bol.com.br
} 


\section{INTRODUÇÃO}

A cultura do feijoeiro destaca-se como uma das mais importantes no âmbito nacional, uma vez que o feijão é produto indispensável na alimentação do brasileiro, fazendo parte dos produtos que compõem a cesta básica. Segundo Gonçalves; Vegro (2006), a produção nacional cresceu mais de 60\%, saindo de 2,2 milhões de toneladas no ano agrícola 1997/98 para 3,67 milhões de toneladas no ano agrícola 2005/06. Grande parte da produção do feijão brasileiro vem de pequenas e médias propriedades (AIDAR; KLUTHCOUSKI, 2004), embora venha ganhando importância também nas grandes empresas agropecuárias, por conta da evolução na mecanização da colheita da cultura.

Segundo Pereira; Machado (1987), o desenvolvimento de culturas anuais pode ser dividido em três fases principais: (a) fase inicial, normalmente apresentando crescimento lento (momento do estabelecimento), (b) intermediária, com crescimento rápido (consolidação da cultura) e (c) fase final, de maturação, cujo crescimento é pequeno ou nulo. Entretanto, a duração de cada fase da planta sofre influência direta do ambiente edáfico, especialmente das condições de preparo e manejo do solo.

Os sistemas de preparo do solo determinam as condições físicas, químicas e biológicas para o crescimento das plantas e produtividade das culturas. Segundo Tormena et al. (2002), os sistemas de cultivo mínimo e preparo convencional do solo proporcionam condições físicas menos restritivas ao crescimento das plantas, quando comparado com o plantio direto. Entretanto, as respostas do feijoeiro dependem do tipo de solo e da cobertura sobre ele existente. Estudos realizados por Mullins et al. (1988) e Landers (1995), relacionando manejo de solo com a cultura do feijão, não mostraram diferenças no rendimento do feijoeiro nos diversos sistemas de manejo do solo. Entretanto, Siqueira et al. (1993), estudando sistemas de cultivo para feijão, observaram-se melhores rendimentos desta leguminosa no manejo com aração e Kluthcouski et al. (2000), verificaram que a aração profunda do Latossolo Roxo com textura franco-argilo arenosa que estudavam, resultou em significativo incremento da produção, quando comparado com manejos sob plantio direto, grade aradora ou escarificação profunda. Por outro lado, Merten (1994) e Silva et al. (1996), estudando a produtividade do feijoeiro em diferentes sistemas de produção, verificaram superioridade do plantio direto no rendimento da cultura, quando comparado com sistema de cultivo convencional. Boller \& Caldato (2001) notaram que os sistemas conservacionistas propiciaram maior viabilidade (técnica e econômica) para o cultivo do feijoeiro, quando comparados com sistemas sem cobertura do solo. Em estudo relacionando efeitos de coberturas do solo com a produção do 
feijoeiro, Nunes et al. (2006) também verificaram que a presença de cobertura vegetal sobre o solo promoveu melhor produção da cultura em sistema de plantio direto, sobretudo com uso de espécies dos gêneros Panicum e Brachiaria.

Diante do exposto, conduziu-se o presente trabalho, que teve como objetivo estudar o desenvolvimento e produtividade do feijoeiro em diferentes sistemas de preparo do solo.

\section{MATERIAL E MÉTODOS}

O trabalho foi conduzido no outono-inverno do ano agrícola 2003/04, na Fazenda de Ensino e Pesquisa da Faculdade de Ciências Agrárias da UNICASTELO, Campus de Fernandópolis, SP, em um Argissolo de textura arenosa, com as seguintes coordenadas geográficas: $21^{\circ} 15^{\prime} 22^{\prime \prime}$ S e $48^{\circ} 15^{\prime} 18^{\prime \prime}$ W. O clima é do tipo Cwa, segundo a classificação de Koppen, isto é, subtropical, temperado, seco no inverno, temperatura média máxima superior a $22^{\circ} \mathrm{C}$, e pluviosidade que varia de $100 \mathrm{~mm}$ (no inverno) a $150 \mathrm{~mm}$ (no verão). O nível de fertilidade do solo no início do experimento encontra-se apresentado na Tabela 1.

Tabela 1- Características químicas do solo na camada 0-0,20m antes da instalação do experimento na área, no ano agrícola 2003/04.

\begin{tabular}{|c|c|c|c|c|c|c|c|c|c|}
\hline PH & M.О. & $\mathrm{P}_{\text {res }}$ & K & $\mathrm{Ca}$ & $\mathrm{Mg}$ & $\mathrm{H}+\mathrm{Al}$ & SB & CTC & V \\
\hline$\left(\mathrm{CaCl}_{2}\right)$ & $\left(\mathrm{mg} \mathrm{kg}^{-1}\right)$ & $\left(\mathrm{mg} \mathrm{dm}^{-3}\right)$ & 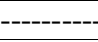 & --"-- & $-\mathrm{mm}$ & ${ }^{-3}-\cdots$ & & -- & $(\%)$ \\
\hline 5,3 & 12,0 & 5,0 & 1,8 & 12,0 & 4,0 & 17,0 & 17,8 & 34,8 & 51,1 \\
\hline
\end{tabular}
SP.

\section{Delineamento experimental e tratamentos}

O experimento foi instalado em delineamento de blocos ao acaso (DBC), com três tratamentos e quatro repetições em parcelas de $1,5 \mathrm{~m}^{2}$ de área, com dimensões de 1,5 x 1,0m. Os tratamentos utilizados no inverno foram: PC: semeadura convencional de feijão, com revolvimento do solo; CM: sistema de cultivo mínimo de feijão, com revolvimento mínimo do solo e controle químico de plantas infestantes e PD: semeadura de feijão em sistema de plantio direto, sem revolvimento do solo e controle químico de plantas infestantes. 


\section{Preparo da área}

Para as parcelas destinadas ao tratamento em sistema de plantio convencional, revolveu-se o solo manualmente com auxílio de enxadão até a profundidade média de $0,20 \mathrm{~m}$. Sete dias após o primeiro revolvimento, realizou-se um segundo revolvimento do solo, mais superficial, correspondente ao preparo secundário do solo. Nas parcelas destinadas ao cultivo mínimo, realizou-se apenas um revolvimento, correspondente a uma operação de preparo primário do solo, até a profundidade média de $0,15 \mathrm{~m}$. Nos tratamentos em sistema de semeadura direta, realizou-se aplicação de herbicida dessecante em área total, utilizando-se 3,0 $\mathrm{L} \mathrm{ha}^{-1}$ de glifosato em $300 \mathrm{~L} \mathrm{ha}^{-1}$ de calda. Após o preparo da área, efetuou-se a abertura do sulco e semeadura propriamente ditos. Após a instalação do ensaio, as parcelas foram irrigadas de acordo com a necessidade, de forma a manter a umidade próxima à da capacidade de campo.

\section{Adubação e tratos culturais}

A adubação de semeadura foi realizada em função da análise química do solo (Tabela 1) e das recomendações técnicas para o Estado de São Paulo, de acordo com Raij, et al. (1997), aplicando-se $384 \mathrm{~kg} \mathrm{ha}^{-1}$ da fórmula comercial 4-14-8, fornecendo 18,7 $\mathrm{kg} \mathrm{ha}^{-1} \mathrm{de} \mathrm{N}$, $53,3 \mathrm{~kg} \mathrm{ha}^{-1}$ de $\mathrm{P}_{2} \mathrm{O}_{5}$ e 30,7 $\mathrm{kg} \mathrm{ha}^{-1}$ de $\mathrm{K}_{2} \mathrm{O}$. Para controle de larva minadora (Phyllocnistis citrella) utilizou-se inseticida deltametrina (n.c.), na dose de $50 \mathrm{ml} \mathrm{ha}^{-1}$ (p.c.), utilizando-se

$6001 \mathrm{ha}^{-1}$ de calda. Para controle de plantas infestantes, foram utilizadas capina manual nas parcelas com cultivo convencional e herbicida nas destinadas ao cultivo mínimo e plantio direto.

\section{Desenvolvimento e produção de matéria seca de feijoeiro}

O desenvolvimento das plantas de feijoeiro foi acompanhado mediante a realização de medições semanais da planta, durante sete semanas. A altura das plantas de feijoeiro foi medida da base, rente ao solo, até a última folha emitida na semana, utilizando-se uma fita métrica. Na primeira medição (16/06/2004), realizada 15 dias após a semeadura da cultura, identificaram-se 10 plantas por parcela com barbante de algodão, nas quais se realizaram as medidas semanais. As demais medidas foram realizadas nos dias 22/06, 29/06, 06/07, 13/07, 20/07 e 26/07/2004. Na oitava semana, coletaram-se duas plantas por parcela para se estimar 
a produção de matéria seca. O material coletado foi colocado em sacos de papel e levados para o laboratório, onde foi separado em vagens e plantas. Após ser pesado, o material foi seco em estufa com circulação forçada de ar regulada a $60-70{ }^{\circ} \mathrm{C}$ e pesadas novamente para obtenção de matéria seca, após atingirem peso constante. Os dados obtidos foram transformados em toneladas por hectare de matéria seca produzida no momento da amostragem.

\section{Produção de grãos}

A produção de grãos de feijão foi realizada coletando-se todas as plantas de cada parcela, que foram transferidas para sacos plásticos devidamente identificados e levados para o laboratório, onde ocorreram separação dos grãos da vagem, limpeza e pesagem. Os dados foram transformados em $\mathrm{t} \mathrm{ha}^{-1} \mathrm{e}$ analisados estatisticamente.

\section{Análise estatística dos dados}

Após a realização das análises previstas, os dados obtidos foram devidamente tabulados e posteriormente submetidos a análises de variância pelo Teste F. Nos casos em que se verificaram efeitos significativos $(\mathrm{P}<0,05)$, aplicou-se o teste de Tukey para comparação de médias (PIMENTEL-GOMES; GARCIA, 2002).

\section{RESULTADOS E DISCUSSÃO}

Os dados coletados durante a condução do ensaio encontram-se apresentados nas Tabelas de 1 a 3 e Figuras de 1 a 3.

Na Tabela 1, estão apresentados os dados de umidade do solo, nos quais pode-se verificar que o maior valor médio foi obtido no tratamento com cultivo convencional, comparado com os valores observados nos tratamentos com cultivo mínimo e plantio direto, fato possivelmente explicado pela maior densidade do solo nessa camada, como mostrado na Tabela 2.

Analisando-se os valores de umidade nas profundidades, pode-se observar que a camada 0,10-0,15m estava significativamente mais úmida, comparada com a camada superficial do solo $(0-0,05 \mathrm{~m})$, o que era de se esperar, uma vez que as camadas superiores tendem a perder água com maior facilidade. 
Tabela 1 - Umidade atual do solo (\%) após a colheita do feijoeiro de inverno, no ano agrícola 2003/04 (média de 4 repetições).

\begin{tabular}{lcccc}
\hline \multirow{2}{*}{ Tipo de Manejo } & \multicolumn{3}{c}{ Profundidades $(\mathrm{m})$} & \multirow{2}{*}{ Média } \\
\cline { 2 - 4 } & $0-0,05$ & $0,05-0,10$ & $0,10-0,15$ & \\
\hline $\mathrm{PC}$ & 8,1 & 5,6 & 7,1 & $7,42 \mathrm{~A}$ \\
$\mathrm{CM}$ & 3,3 & 6,5 & 7,7 & $5,33 \mathrm{~B}$ \\
$\mathrm{PD}$ & 3,7 & 5,9 & 7,5 & $5,68 \mathrm{AB}$ \\
\hline Média & $5,03 \mathrm{~b}$ & $6,00 \mathrm{ab}$ & $7,04 \mathrm{a}$ & \\
\hline $\mathrm{F}_{\mathrm{T}}=5,59^{*}$ & $\mathrm{~F}_{\mathrm{Pr}}=4,15^{*}$ & $\mathrm{~F}_{\mathrm{T}} \mathrm{X}_{\mathrm{Pr}}=1,78^{\mathrm{NS}}$ & & $\mathrm{CV}_{\mathrm{T}}=26,65 \%$ \\
$\mathrm{P}<0,05$ & $\mathrm{P}>0,05$ & $\mathrm{P}<0,05$ & $\mathrm{CV}_{\mathrm{Pr}}=33,04 \%$ \\
\hline $\mathrm{PC}$
\end{tabular}

$\mathrm{PC}=$ cultivo convencional, $\mathrm{CM}=$ cultivo mínimo, $\mathrm{PD}=$ Plantio direto; $\mathrm{T}=$ tipo de preparo, $\mathrm{Pr}$ = profundidade; Letras maiúsculas comparam médias dispostas na vertical e minúsculas na horizontal. Médias seguidas de mesma letra não diferem entre si ao nível de $5 \%$ de probabilidade, pelo Teste de Tukey. NS $=(\mathrm{P}>0,05) ; *=(\mathrm{P}<0,05) ; * *=(\mathrm{P}<0,01)$.

Os valores de densidade do solo encontram-se na Tabela 2. Os valores médios para profundidade indicam menor densidade na camada $0-0,05 \mathrm{~m}$, comparada às camadas mais profundas. Analisando-se os valores de cada tratamento nesta camada, verifica-se que o tratamento sob cultivo mínimo $(\mathrm{CM})$ apresentou a menor densidade, quando comparado com o cultivo convencional (PC). Embora seja o primeiro ano de cultivo, os dados mostram que o solo revolvido, que tende a apresentar menor densidade logo após a mobilização, sofre adensamento durante o ciclo da cultura. Este comportamento pode ser atribuído à reorganização das partículas do solo que, ao serem desagregadas pelo processo de mobilização durante o preparo, tornam-se menores. Embora alguns autores (ELTZ et al. 1989; BERTOL et al. 1997) tenham mostrado que o sistema de plantio direto apresenta maior densidade superficial, mostraram também que o sistema produz, ao longo do tempo, agregados estáveis em água de maior tamanho, possivelmente devido à não destruição mecânica dos agregados pelos equipamentos de preparo do solo, o que poderia explicar, em parte, a menor densidade encontrada no CM neste estudo. Considerando-se os tratamentos utilizados, pode-se verificar que os sistemas de CM e PD tiveram comportamentos semelhantes quanto à densidade, apresentando menores valores na camada superficial (00,05m). Considerando que o feijoeiro é uma planta com sistema radicular vigoroso e com maior concentração nas camadas superficiais, é possível que as raízes tenham contribuído com o resultado observado, associadas à pouca $(\mathrm{CM})$ ou nenhuma $(\mathrm{PD})$ mobilização do solo. Os dados de resistência do solo à penetração (RSP) estão apresentados na Tabela 3. De forma geral, pode-se verificar que a menor RSP foi observada no tratamento sob sistema de cultivo convencional. 
Tabela 2 -Densidade aparente $\left(\mathrm{g} \mathrm{cm}^{-3}\right)$ do solo após a colheita do feijoeiro de inverno, no ano agrícola 2003/04.

\begin{tabular}{|c|c|c|c|c|c|}
\hline \multirow{2}{*}{ Tipo de Manejo } & \multicolumn{3}{|c|}{ Profundidades (m) } & \multirow{2}{*}{ Média } & \multirow{2}{*}{ Teste F } \\
\hline & $0-0,05$ & $0,05-0,10$ & $0,10-0,15$ & & \\
\hline $\mathrm{PC}$ & 2,08 a $A$ & 2,18 a $A$ & 2,13 a $A$ & $2,10 \mathrm{~A}$ & $11,79^{* *}$ \\
\hline $\mathrm{CM}$ & $1,75 \mathrm{~b} \mathrm{~B}$ & 2,20 a $\mathrm{A}$ & 2,13 a $A$ & $2,03 \mathrm{~A}$ & $0,13^{\mathrm{NS}}$ \\
\hline PD & $1,83 \mathrm{~b} \mathrm{AB}$ & 2,10 a $A$ & 2,20 a $A$ & $2,04 \mathrm{~A}$ & $7,65^{* *}$ \\
\hline Média & $1,88 \mathrm{~b}$ & $2,13 \mathrm{a}$ & $2,15 \mathrm{a}$ & $\mathrm{CV}_{\mathrm{T}}=8,98 \%$ & \\
\hline Teste F & $4,77 *$ & $0,55^{\mathrm{NS}}$ & $0,31^{\mathrm{NS}}$ & $\mathrm{CV}_{\mathrm{Pr}}=6,83 \%$ & \\
\hline
\end{tabular}

Analisando-se os dados obtidos para o tratamento sob cultivo mínimo, observa-se que as menores RSP foram observadas nas camadas $0,05-0,10 \mathrm{~m}$ e $0,10-0,15 \mathrm{~m}$, significativamente diferentes daquela observada na camada $0,30-0,35 \mathrm{~m}$. Por se tratar de um tratamento com revolvimento mínimo do solo, a heterogeneidade da operação pode ser uma explicação para o efeito observado.

Tabela 3- Resistência do solo à penetração (Imp. $\mathrm{dm}^{-1}$ ) após a colheita do feijoeiro de inverno no ano de 2004 (média de 8 repetições).

\begin{tabular}{|c|c|c|c|c|c|}
\hline \multirow{2}{*}{$\begin{array}{l}\text { Profundidade } \\
\text { (m) }\end{array}$} & \multicolumn{3}{|c|}{ Tipos de Manejo } & \multirow{2}{*}{ Média } & \multirow{2}{*}{ Teste F } \\
\hline & PC & $\mathrm{CM}$ & PD & & \\
\hline $0-0,05$ & $2,0 \mathrm{~A} \mathrm{~b}$ & $7,0 \mathrm{AB}$ a & $5,8 \mathrm{~B} \mathrm{a}$ & $4,9 \mathrm{~A}$ & $8,68^{* *}$ \\
\hline $0,05-0,10$ & $2,0 \mathrm{~A} \mathrm{~b}$ & $4,0 \mathrm{~B} \mathrm{~b}$ & $8,8 \mathrm{AB}$ a & $4,9 \mathrm{~A}$ & $15,41^{* * *}$ \\
\hline $0,10-0,15$ & $3,0 \mathrm{~A} \mathrm{~b}$ & $4,3 \mathrm{~B} \mathrm{~b}$ & $7,5 \mathrm{AB}$ a & $4,9 \mathrm{~A}$ & $6,92^{* *}$ \\
\hline $0,15-0,20$ & $2,0 \mathrm{~A} \mathrm{~b}$ & 7,3 AB a & $5,3 \mathrm{~B} \mathrm{a}$ & $4,8 \mathrm{~A}$ & $9,00^{* *}$ \\
\hline $0,20-0,25$ & $2,0 \mathrm{~A} \mathrm{~b}$ & $6,5 \mathrm{AB} b$ & $10,5 \mathrm{~A} \mathrm{a}$ & $6,3 \mathrm{~A}$ & $23,19^{* *}$ \\
\hline $0,25-0,30$ & $3,8 \mathrm{~A} \mathrm{~b}$ & $6,3 \mathrm{AB}$ a & $6,0 \mathrm{~B} \mathrm{a}$ & $5,3 \mathrm{~A}$ & $2,43^{\mathrm{NS}}$ \\
\hline $0,30-0,35$ & $2,5 \mathrm{~A} \mathrm{~b}$ & $8,8 \mathrm{~A} \mathrm{a}$ & $5,3 \mathrm{~B} \mathrm{~b}$ & $5,5 \mathrm{~A}$ & $12,58^{* *}$ \\
\hline $0,35-0,40$ & $3,8 \mathrm{~A} \mathrm{~b}$ & $6,8 \mathrm{AB} \mathrm{a}$ & $9,0 \mathrm{AB}$ a & $6,5 \mathrm{~A}$ & $8,89^{* *}$ \\
\hline Média & $2,6 \mathrm{~b}$ & $6,3 \mathrm{a}$ & $7,3 \mathrm{a}$ & $\mathrm{CV}_{\mathrm{T}}=40,7 \%$ & \\
\hline Teste F & $0,75^{\mathrm{NS}}$ & $3,04^{* *}$ & $4,93^{* *}$ & $\mathrm{CV}_{\mathrm{Pr}}=46,94 \%$ & \\
\hline
\end{tabular}

$\mathrm{PC}=$ plantio convencional, $\mathrm{CM}=$ cultivo mínimo, $\mathrm{PD}=$ Plantio direto; $\mathrm{T}=$ tipo de preparo, $\mathrm{Pr}$ = profundidade; Letras maiúsculas comparam médias dispostas na vertical e minúsculas na horizontal. Médias seguidas de mesma letra não diferem entre si ao nível de $5 \%$ de probabilidade, pelo Teste de Tukey. $\mathrm{NS}=(\mathrm{P}>0,05) ; * *=(\mathrm{P}<0,01)$.

Com relação ao tratamento sob sistema de plantio direto, observa-se que a maior RSP foi verificada na camada $0,20-0,25 \mathrm{~m}$, significativamente superior àquelas observadas nas camadas acima $(0-0,05 \mathrm{~m}$ e $0,15-0,20 \mathrm{~m})$ e abaixo $(0,25-0,30 \mathrm{~m}$ e $0,30-0,35 \mathrm{~m})$. 
Como se pode observar, os dados sugerem a presença de uma camada adensada em uma região onde é comum o tráfego dos órgãos ativos de máquinas para preparo do solo como arados de discos. Considerando-se que antes da instalação do experimento não foi realizada operação de subsolagem, a camada adensada em questão parece corresponder a um pé-de-arado ou pé-de-grade.

O desenvolvimento das plantas de feijoeiro foi acompanhado por oito semanas após a semeadora e os dados obtidos encontram-se apresentados na Figura 1.

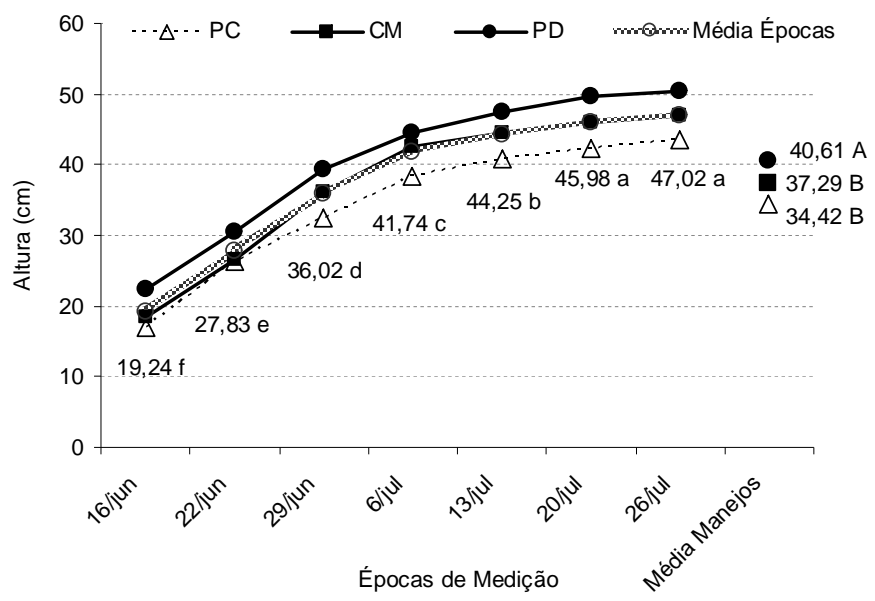

Figura 1 - Desenvolvimento de plantas de feijoeiro cultivadas em argissolo, no inverno do ano de 2004. Os números indicam médias. Médias seguidas de mesma letra minúscula (épocas de medição) e mesma letra maiúscula (Manejos) não diferem entre si $(\mathrm{P}<0,05)$ pelo Teste de Tukey. PC - plantio convencional, $\mathrm{CM}$ - cultivo mínimo, PD - plantio direto.

Observando-se os dados, pode-se verificar que houve crescimento significativo das plantas de feijoeiro de uma semana para outra, observando-se estabilidade no crescimento, aproximadamente aos 40 dias após a semeadura. Já, comparando-se os tipos de manejo, a maior altura média foi obtida no sistema de plantio direto, em relação ao cultivo mínimo e cultivo convencional. Esta tendência começou a ser delineada desde a primeira medição, realizada em 16/06/2004, uma vez que o tratamento PD mostrou maior altura média em todas as semanas (Figura 1). As plantas cultivadas no sistema de cultivo mínimo e cultivo convencional tiveram alturas estatisticamente semelhantes durante todo o período de avaliação.

O maior desenvolvimento médio da cultura no sistema de PD pode indicar que o ambiente de produção apresentou-se mais favorável ao feijoeiro, como menor variação térmica (PEZZOPANE et al. 1996), maior estabilidade de agregados (PERUSI; CARVALHO, 2007) e proteção do solo pela cobertura vegetal (SOUZA; MELO, 2003). 


\section{Produção de matéria seca e de grãos}

A produção de matéria seca das plantas de feijoeiro e de vagens foi medida na oitava semana após a semeadura, cujos dados encontram-se apresentados na Figura 2. Analisando-se os dados, não se verificou diferenças significativas entre os tratamentos estudados, seja para planta, vagem ou matéria seca total. Este comportamento poderia ser esperado, considerando que se trata do primeiro ano de instalação dos sistemas de cultivo na área e que, efeitos de cultivo em estudos desta natureza ocorrem normalmente a médio e longo prazos.

A tendência de maior produção de matéria seca nos tratamentos PC e CM (Figura 2), mostram que os dados obtidos estão de acordo com os da literatura, uma vez que Tormena et al. (2002) também encontraram resultados semelhantes. Segundo os autores, os sistemas de cultivo mínimo e plantio convencional proporcionam condições físicas menos restritivas ao crescimento das plantas, quando comparados com o plantio direto, o que pode refletir na produção de grãos.

A produtividade da cultura do feijoeiro foi estimada ao final do ciclo da cultura e os dados encontram-se apresentados na Figura 3. Assim como observado para os dados de produção de matéria seca, a produção de grãos também se mostrou semelhante em todos os tratamentos estudados, o que tende a confirmar o discutido acima, a respeito de respostas esperadas para ensaios com sistemas de produção agrícola.

Os dados obtidos estão de acordo com os encontrados na literatura, que indicam a necessidade de estudos com períodos mais longos para se observar efeitos de tratamentos em estudos desta natureza. Mullins (1988) e Landers (1995), estudando a cultura do feijoeiro em diferentes sistemas de preparo do solo, também não verificaram diferenças significativas de produtividade entre o plantio direto e convencional. 


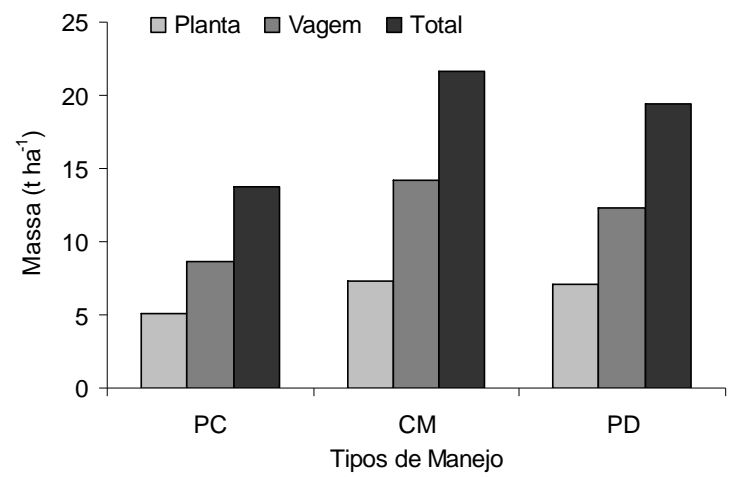

Figura 2. Produção de matéria seca de feijoeiro cultivado em argissolo, no inverno do ano de 2004. PC - plantio convencional, CM - cultivo mínimo, PD plantio direto.

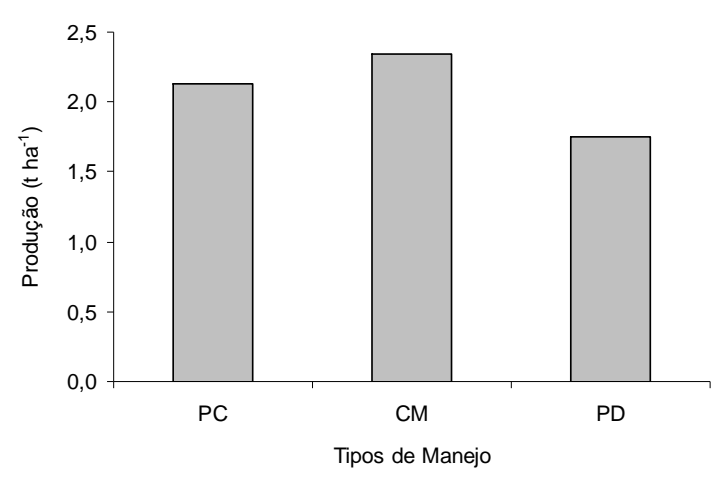

Figura 3. Produção de grãos de feijão cultivado em argissolo, no inverno do ano de 2004. PC - plantio convencional, CM - cultivo mínimo, PD - plantio direto.

\section{CONCLUSÃO}

De acordo com os dados apresentados e para as condições deste estudo, pode-se concluir que o plantio convencional apresentou maior umidade atual na camada superior, possivelmente em função da maior densidade nela observada; as maiores RSP foram observadas nos tratamentos sob cultivo mínimo e plantio direto, como conseqüência da pouca (CM) ou nenhuma (PD) mobilização do solo; o desenvolvimento médio das plantas de feijoeiro foi maior no sistema de plantio direto; todos os sistemas de preparo estudados mostraram produção de matéria seca e de grãos semelhantes, indicando que o maior desenvolvimento não se refletiu nesses parâmetros. Há necessidade de prolongar o estudo, para que respostas conclusivas possam ser obtidas para a região Noroeste Paulista.

\section{REFERÊNCIAS}

AIDAR, H; KLUTHCOUSKI, J. Embrapa Arroz e Feijão. Sistemas de Produção 4, Versão Eletrônica, dez./2004 Produção de sementes sadias de feijão comum em várzeas tropicais: introdução e importância econômica. Disponível em: http://sistemasdeproducao.cnptia.embrapa.br/FontesHTML/Feijao/FeijaoVarzeaTropical/inde x.htm. Acesso em: 06 mar. 2008.

BERTOL, I; COGO, N. P; LEVIEN, R. Erosão hídrica em diferentes preparos do solo logo após as colheitas de milho e trigo, na presença e na ausência dos resíduos culturais. Rev. Brás. Ciênc. Solo, v.21, n.3, p.409-18, 1997. 
BOLLER, W; CALDATO, D. E. Desenvolvimento da cultura do feijão (Phaseolus vulgaris L.) em diferentes condições de cobertura e preparo do solo. Eng. Agric., v. 21, n.2, p.167$173,2001$.

ELTZ, F. L. F; PEIXOTO, R. T. G; JASTER, F. Efeitos de sistemas de preparo do solo nas propriedades físicas e químicas de um latossolo bruno álico. Rev. Brás. Ciênc. Solo, v.13, n.2, p.259-67, 1989.

GONÇALVES, J. S; VEGRO, C.L.R. Programas sociais, o arroz com feijão e o pão nosso de cada dia. Análises e indicadores do agronegócio, v.1, n.9, 2006. Disponível em: http://www.iea.sp.gov.br/out/verTexto.php?codTexto=7312. Acesso em: 06 mar. 2008.

KLUTHCOUSKI, J. et al. Manejo do solo e o rendimento de soja, milho, feijão e arroz em plantio direto. Sci. agric. v.57, n.1, 2000. p.97-104.

LANDERS, J. N. Fascículo de experiências de plantio direto no cerrado. Goiânia: APDC, 1995. 261p.

MERTEN, G. H. Rendimento de grãos de feijão em diferentes sistemas de preparo do solo com tração animal. In: REUNIÃO BRASILEIRA DE MANEJO E CONSERVAÇÃO DO SOLO E DA ÁGUA, 10, Florianópolis, 1994, Florianópolis. Anais... Florianópolis: Sociedade Brasileira de Ciência do Solo, 1994. p.178-179.

MULLINS, C. A; STRAW, R.A. Production of snap beans as effected by soil tillage method and row spacing. Journal of The American Society for Horticultural Science, v.113, n.5, p.667-669, 1988.

NUNES, U. R. et al. Produção de palhada de plantas de cobertura e rendimento do feijão em plantio direto. Pesq. Agropec. Brás., v.41, n.6, p.943-948, 2006.

PEREIRA, A. R; MACHADO, E. C. Análise quantitativa do crescimento de comunidade vegetal. Campinas: Instituto Agronômico, 1987. 33p. (Boletim Técnico, 114).

PERUSI, M. C; CARVALHO, W. A. Avaliação da estabilidade de agregados de argissolos em diferentes sistemas de uso e manejo no município de Anhumas, SP. Energia na Agricultura, v. 22, n.1, p.94-111, 2007.

PEZZOPANE, J. E. M. et al. Temperatura do solo em função da cobertura morta por palha de café. Rev. Bras. Agromet., v.4, n.2, p.7-10, 1996.

PIMENTEL GOMES, F; GARCIA, C. H. Estatística aplicada a experimentos agronômicos e florestais. Piracicaba: FEALQ, 2002. 309p.

RAIJ, B. Van et al. Recomendações de adubação e calagem para o Estado de São Paulo. 2.ed. Campinas, Instituto Agronômico, 1997. p.56-61 (Boletim Técnico, 100). 
SILVA, V. A; ANDRADE, M. J. B; RAMALHO, M. A. P. Efeitos de métodos de preparo do solo e níveis de fertilizante NPK sobre o feijão da "seca" (Phaseolus vulgaris L.) em sequiência à cultura do milho. In: REUNIÃO NACIONA DE PESQUISA DE FEIJÃO, 5, Goiânia, 1996. Anais. Goiânia: EMBRAPA, CNPAF, 1996. v.1. p.418-420. (Documentos, 69).

SIQUEIRA, R; YAMAOKA, R. S; CASÃO JÚNIOR, R. Sistemas de preparo e coberturas vegetais em um solo de baixa aptidão agrícola. In: ENCONTRO LATINO AMERICANO SOBRE PLANTIO DIRETO NA PEQUENA PROPRIEDADE, 1., Ponta Grossa, 1993. Anais... Ponta Grossa:IAPAR, 1993. p.221-237.

SOUZA, W. J. O; MELO, W. J. Matéria orgânica em um latossolo submetido a diferentes sistemas de produção de milho. Rev. Bras. Cienc. Solo, v.27, p.1113-1122, 2003.

TORMENA, C. A; BARBOSA, M. C; COSTA, A.C. S. Densidade, porosidade e resistência à penetração em Latossolo cultivado sob diferentes sistemas de preparo do solo. Sci. Agric., v.59, n.4, p.795-801, 2002. 